Proceedings of the 2012 Winter Simulation Conference

C. Laroque, J. Himmelspach, R. Pasupathy, O. Rose, and A. M. Uhrmacher, eds.

\title{
EMBEDDED SIMULATION FOR AUTOMATION OF MATERIAL MANIPULATORS IN A PVD COATING PROCESS
}

\author{
Gerhard Rath \\ University of Leoben \\ Peter-Tunner-Str. 27 \\ A-8700 Leoben, AUSTRIA
}

\author{
Jürgen M. Lackner \\ Joanneum Research \\ Leobner Strasse 94 \\ A-8712 Niklasdorf, AUSTRIA
}

\author{
Wolfgang Waldhauser \\ Joanneum Research \\ Leobner Strasse 94 \\ A-8712 Niklasdorf, AUSTRIA
}

\begin{abstract}
For the automation of a production system a hardware-in-the-loop (HIL) simulation model of the mechanical system was developed and embedded on the controller. In a second level, the controller was simulated on a PC for designing and testing the human-machine interface (HMI). The task of the system is a PVD (physical vapor deposition) coating process for materials, which involves pulsed laser deposition and magnetron sputtering. It requires positioning devices to move material probes as well as to manipulate laser target materials in a vacuum chamber. As a result of using simulation, the start-up phase was shortened and production was resumed faster. The need of software changes after deployment was reduced. With the increasing capabilities of modern simulation software and controller hardware it turns out, that virtual start-up, factory acceptance test and functional validation are practicable also for small projects.
\end{abstract}

\section{INTRODUCTION}

\subsection{The PVD Process}

Physical Vapor Deposition (PVD) is a general term for a variety of methods to deposit thin films by the condensation of a vaporized form of the material onto various surfaces. PVD coating method is widely used for decorative and functional coatings and is normally performed in a vacuum chamber. Coating materials can be TiC, TiCN, ZrN, CrN, MoS2, TiAlCN, TiN-AIN, CNx, DLC (diamond-like carbon), ta-C (tetrahedral amorphous carbon) and metals and alloys. In various industrial PVD technologies, Cathodic Arc Deposition and Magnetic Sputtering are mainly used nowadays. Pulsed Laser Deposition (PLD) is a well-established laboratory coating technology. The roots date back to the 1960s. Up to now PLD has not become a standard industrial coating technique despite its outstanding process features. The missing of PLD coating systems which fulfill the requirements for industrial applications is considered as one of the main obstacles for a breakthrough of the PLD technique. To overcome this problem a computer controlled Hybrid PLD coating system has been developed and built-up at Joanneum Research which combines the processes Magnetic Sputtering and Pulsed Laser Deposition (Ebner, Waldhauser, and Lenz 2001; Lackner and Waldhauser 2005; Waldhauser and Lackner 2006). Sputtering is a process whereby atoms are ejected from a solid target material due to bombardment of the target by energetic particles. It is commonly used for thin-film deposition, etching and analytical techniques. The average number of atoms ejected from the target per incident ion is called the sputter yield and depends on the ion incident angle, the energy of the 


\section{Rath, Lackner, and Waldhauser}

ion, the masses of the ion and target atoms, and the surface binding energy of atoms in the target. For thin film deposition a glow plasma discharge (usually localized around the target by a magnet) bombards the material sputtering some away as a vapor for subsequent deposition. Since the target being fixed on the sputtering cathode is statically mounted a directional vapor plume is available in the coating chamber. Therefore for coating of three-dimensional parts a movement and rotation of the substrates is necessary. This can be realized by a substrate carousel enabling a three-axis rotation of the substrates. Pulsed laser deposition systems work by an ablation process (Chrisey and Hubler 1994). Pulses of focused laser light vaporize the surface of the target material and convert it to an ionized vapor. For an optimized ablation process on the surface of the target a relative movement between laser beam and target is necessary. This can be realized on the one hand by scanning of the laser on the static target and on the other hand by a fixed laser beam and a movement of the target. For large area coating several laser beams can be used simultaneously. Since Joanneum Research is applying four fixed laser beams a complex target manipulator (Fig. 1) has to be used (Ebner, Waldhauser, and Lenz 2001; Lackner and Waldhauser 2005; Waldhauser and Lackner 2006).

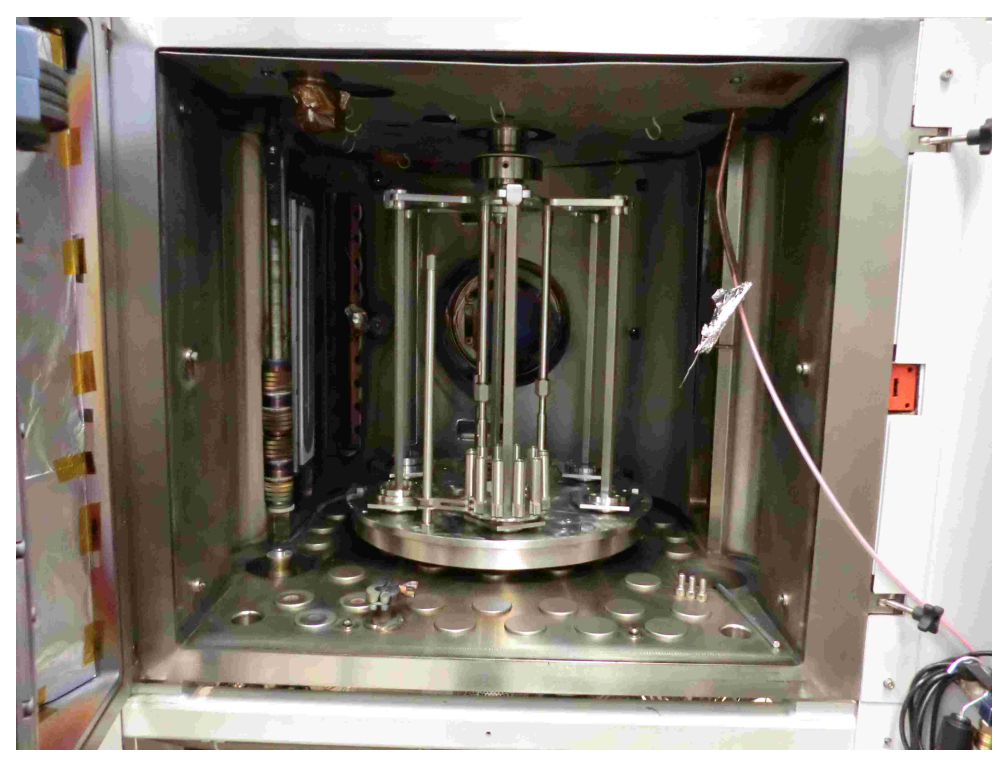

Figure 1: Vacuum chamber of hybrid PVD coating plant (magnetron cathode, PLD targets, substrate carousel).

\subsection{Simulation in Manufacturing Automation}

Simulation is the task to establish a model of a real system in order to make some experiments (Pedgen, Shannon, and Sadowski 1995). The first step in its application is to establish a suitable model, which is the most important task (Lieberman 2007). Models can be of time-continuous or time-discrete character. By nature, computer models are always time-discrete, even when they describe continuous systems. Event based models react to certain stimuli and do not have time as primary variable, for example Finite State Machines or models in early definition of DEVS, discrete event system specification (Zeigler 1976). Modern simulation tools develop towards integration of (quasi) time-continuous, time-discrete and discrete event systems, which is called hybrid simulation (Crosbie 2012).

Simulation was applied first in fields connected with high level of risks, for example for training on flight simulators (Page 2000). Later large scale industry took over this technique for operator training (OTS) in nuclear plants (Perkins 1985), later for chemical and power plants. Reduction of hardware costs 


\section{Rath, Lackner, and Waldhauser}

and the explosion of computing power made simulation attractive for machinery (Freedman 2000) and production systems.

In modern manufacturing, simulation is not only applied for operator training. Process training may be used to improve the knowledge of the system dynamics, simulation may be used during design and planning (Filla and Palmberg 2003), and even makes maintenance more effective (Rath 2008). Important developments were real-time simulators with exactly the same time behavior like the real system. This allows testing of control equipment with a replica of the system under control and is called HIL, hardware in the loop (Isermann, Schaffnit, and Sinsel 1999). In manufacturing, HIL enables a virtual start-up before a system is deployed, furthermore factory acceptance test (FAT) with the customer involved can be made, and functional validation removes understanding mistakes before their appear at start-up time.

Industrial systems with maybe many thousands of input and outputs require a reduction of wiring costs for simulation. Field bus systems avoid wiring for simulation (Fig. 2). Furthermore it is important to import the related variables from the control system to the simulator of the plant, which is accomplished by importing the variables directly from the control system software.

A further step of cost reduction is possible when embedding the simulation software in the control system, where it runs simultaneously with the control program. The increase of computing power even in PLCs in the recent years allows such additional features. First applications of this embedded simulation were found in military systems, where training of personnel may happen during the idle time of weapons (Walters 2000). In contrast to weapons, industrial plants usually should have no idle time, albeit embedded simulation has its advantages. For example, a special simulation mode in rolling mills enables a "dry" run without a work piece for testing purpose (Pfeiler, Köck, Schröder, and Maestrutti 2003). Industrial controllers for electrical drives usually provide some embedded simulation, but without regarding physical reality, since the final purpose of the system is not known a priori to the manufacturer. Many engineers make models for their specific task and run the simulation embedded on the control system in order to test their software without the need of additional hardware. When the project is finished, the simulation may be deleted or left on the system.

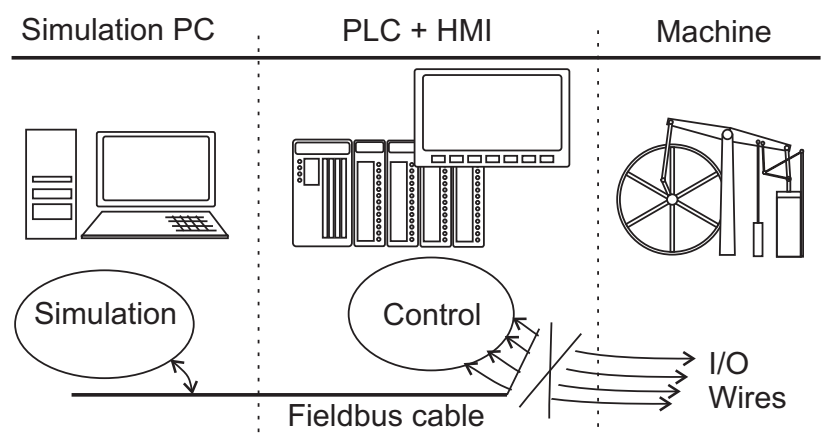

Figure 2: Common configuration of a HIL simulation.

\subsection{Simulation in the Actual Project}

Modern PLCs (programmable logic controllers) contain the same electronic hardware for processing like PCs. Consequently, the computing power is over dimensioned for many classical automation tasks, such as position control, logic control and HMI. This allows shifting new tasks to the PLC level. For example, it is possible to embed simulation models of the mechanical system running in parallel with the control programs (Fig. 3). Compared to the configuration in Fig. 2, there is no serial communication of the process variables necessary. This save costs and allows faster simulation cycles down to a few microseconds. Furthermore, the embedded simulation model may stay on the control system even after the delivery, which is a feature that was not utilized in the actual project. The embedded simulation of the mechanical components of the 
Rath, Lackner, and Waldhauser

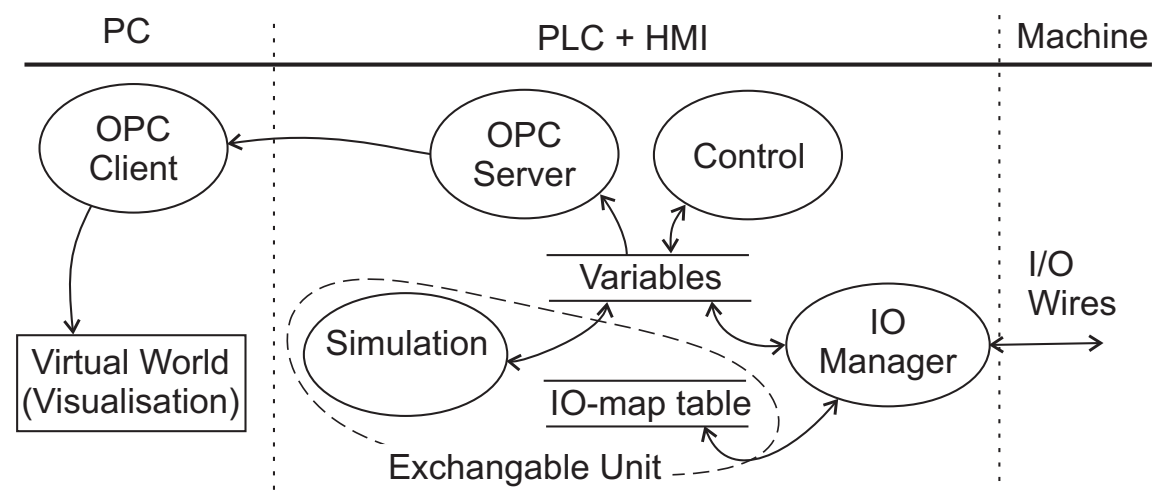

Figure 3: Actual configuration of HIL simulation.

production system according to Fig. 3 is an efficient HIL system. It was used for tests of the control software, in particular to pre-adjust the control loops for the motor drives. Additionally functional validation of the software and factory acceptance test (FAT) took place with the customer involved before the mechanical system was constructed.

Apart from this real-time HIL simulation, a second implementation of simulation was used to develop the requirement specifications of the HMI. In the age of tablets and smart phones, software is designed without the need of reading manuals. Consequently, people do not like to read written requirement specifications for software, but prefer to have test implementations at hand, starting with a rapid prototype. This is a principle used in Extreme Programming (XP), a process model for software development (Beck 1999). The HMI for the machine operator, who controls all functions of the machine on a touch screen, was specified according to this principle without any written documentation. For this purpose, a configuration that is different from the HIL implementation was used. A common technique supported by manufacturers of control systems is to run an emulation of the PLC on the PC for testing and simulation purposes. This means, the PLC environment is a piece of software running on the PC in order to test control software without having a physical specimen of the electronic controller. Of course this mode does not provide real-time operation and does not involve communication and physical inputs and outputs. For our project, this means that all software artifacts in Fig. 3 run on the PC: The machine simulation is embedded in the PLC environment, the PLC and HMI are emulated on the PC. The advantage is that no electronic or mechanical peripheral components are required. The missing real-time property is not essential for the specification and design of the HMI software.

\section{THE SYSTEM AUTOMATION TASK}

The mechanical system to be automated consisted of three main parts. First, a manipulator for the materials to be vaporized by pulsed laser needs three DOF of translation for selecting a material and one DOF of rotation to obtain a homogeneous ablation of the target material. This task is accomplished with four stepper motors (Fig. 4). The three translational axes are equipped with capacitive limit switches for calibration (homing) of the axes and to prevent motions beyond defined limits. The tasks of the automation program are to ensure a homing procedure before starting the work, to scale the axes to convenient units and to do some checks of plausibility, since the axes have no position encoders.

The second part, the carrier for the specimens to be coated (substrates), is a rotating carousel with six planetary axes, each of them holding a stack of specimens and rotating them also (Fig. 1). Some recipes require to move one stack of specimens to a certain position and to rotate the planetary axis, some other demand continuous rotation of all stacks. Two servo motors with incremental angle encoders and gear boxes are used, one for the carousel, and one for the six planetary stacks. 


\section{Rath, Lackner, and Waldhauser}

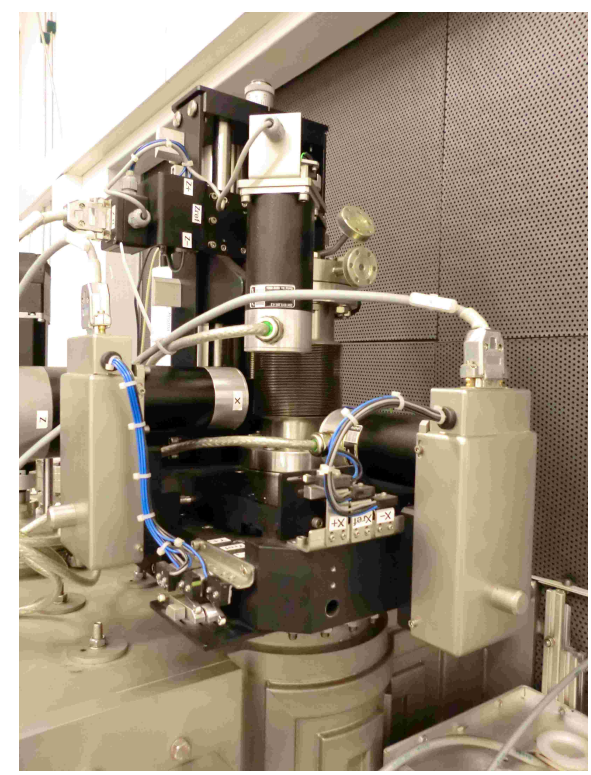

Figure 4: Stepper motor drives for the manipulator.

At the first glance, the automation seemed to be a simple positioning task, but the restriction of the motion strictly to one direction made it more complex. An additional state machine was necessary for positioning and the controller parameters must ensure the correct behavior with this non-linear constraint.

Finally, the third main part is a shutter working as a particle shield, which can be positioned between any of the six stacks and one of the particle sources. Here also a servo motor with gear box and incremental encoder is applied. The shutter uses the same type of drive as the substrate carrier but is allowed to move in both rotational directions. So the electronic control can select the direction in order to optimize the positioning time.

For all axes it was necessary to regard a friction component induced by the vacuum seals for each axis, which was of unknown size before the mechanical construction.

\section{SIMULATION DETAILS}

The hardware for electronic control is a CPU model of the type X201384 by Bernecker \& Rainer company. The simulation, which replicates the behavior of the deployed machine, is embedded on the same hardware (Fig. 3). Both the control and the simulation programs work with the process variables. A table maps some selected variables to physical inputs and outputs to and from the machine. Combining simulation and the map table gives the opportunity to select, which components of the machine are simulated and which are under real control.

The simulation was developed in Matlab ${ }^{\circledR} /$ Simulink ${ }^{\circledR}$. The Simulink coder generates C-code adapted to the desired target PLC. The compiler of the PLC accepts this code and creates a thread running under the control of a real-time operating system.

The PLC and its HMI yield full operability of the system. Additionally it is of advantage to make the simulated system observable like the real one. For this purpose an OPC server sends data to the PC, where a virtual world model of the machine is animated (Fig. 3). The OPC client and the VRML interface are again components of Simulink, the visualization (Fig. 5) is done by a web browser with a VRML plug-in.

\section{Manipulator}

The simple model of a stepper motor drive shown in Fig. 6 should demonstrate an interesting aspect. It is possible to implement finite state machines as well as computations in script language. A look at 


\section{Rath, Lackner, and Waldhauser}

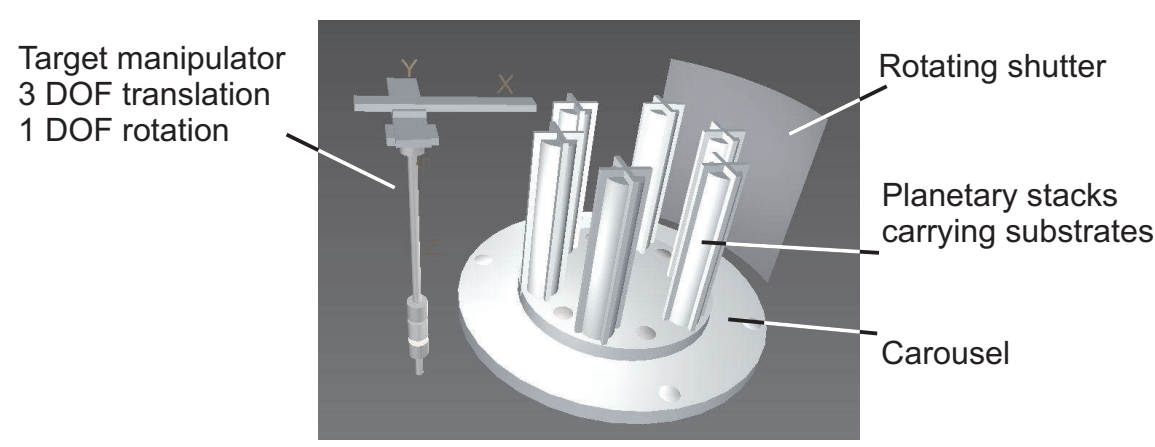

Figure 5: Virtual reality model for visualization.

the integrator, which is a simple continuous time model, shows that the hybrid modeling of discrete and continuous time systems is used here. Modern tools can implement hybrid models without any additional effort.

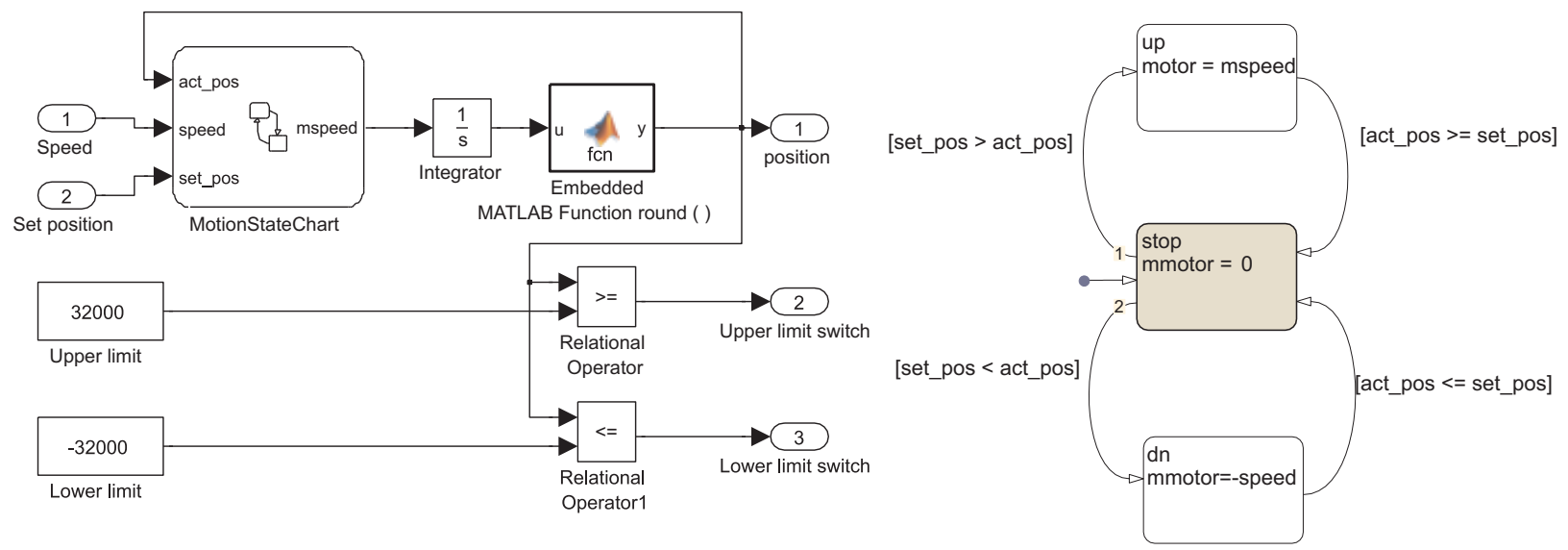

Figure 6: Model of the stepper motor drive unit (left) and the motion state chart detail (right).

\section{Carousel}

Modern controllers for positioning systems provide a mode to enable a simulated motion in order to test the surrounding control logic. In many cases it is necessary to implement also the physical properties of the real hybrid PVD coating plant. With the help of the actual environment, it was possible to model the inertia of the motors and the loads, the gear boxes with backlash, the (roughly estimated) stick-slip of the vacuum seals, and the encoders delivering quantized signals.

\section{Problems}

Making models of real systems for the purpose of simulation is a very interesting job for automation engineers. Bearing in the mind that simulation avoids risk of damage in experiments, one is leaded to forget that an erroneous model may cause severe problems in a later phase of the project. In the actual project we faced one problem of this kind. The friction of the seals under vacuum was much lower than under atmospheric pressure, and the level of detail of the model in Fig. 7 turned out to be too low. It appeared that the angular momentum of the planetary stacks affected the motion of the carousel.

This mistake had to be corrected during the first production test and wasted valuable time. Selecting a higher level of detail for the simulation like in Fig. 8 would have prevented this problem. 

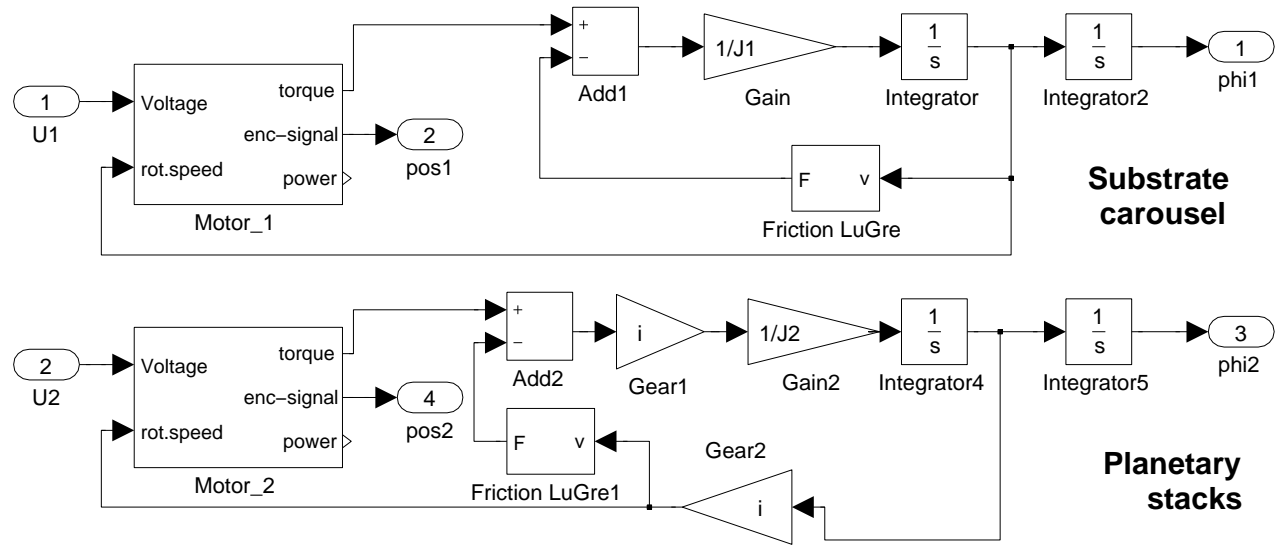

Figure 7: Carousel model, first version.

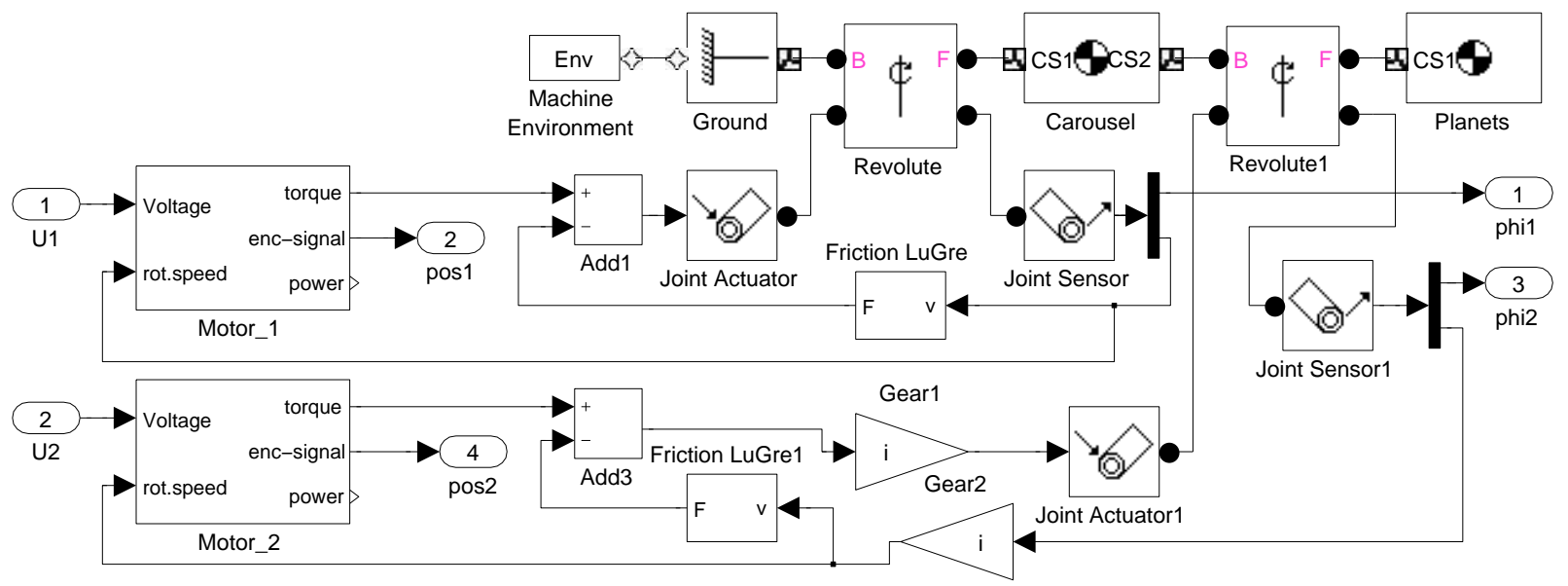

Figure 8: Carousel with complete mechanical model.

\section{GOALS AND EFFECTS OF SIMULATION IN THE ACTUAL PROJEKT}

\subsection{Work on the Simulation Model Before Start-up}

The development of the simulation models required a work of two days, using experience and libraries from former automation projects. Two different configurations were developed. A real-time version embedded on the controller hardware (PLC) for HIL simulation and a second one with the emulation of the PLC system on the PC for the development of the HMI.

\section{Virtual Start-up}

Developing the PLC software for logic control of sequences, position and speed control of the servo motors for the carousel, and governing the stepper motors for the manipulator required a work of three days and ended with the virtual start-up as a milestone. It was essential to find minor bugs in exceptional situations, for example emergency stop, power loss or mechanical disturbances. The virtual start-up saved approximately one day of work during the real start-up and another day during the first production. 


\section{Rath, Lackner, and Waldhauser}

Table 1: Amount of work [hrs].

\begin{tabular}{rcccccc} 
& Design & $\begin{array}{c}\text { Verification } \\
\text { test \& redesign }\end{array}$ & $\begin{array}{c}\text { Virtual startup } \\
\text { \& redesign }\end{array}$ & FAT & Installation & Production \\
\hline Electrical system & 8 & & & 1 & 32 & \\
DC Drives & & & 8 & & 2 & \\
Manipulator & 16 & 4 & 4 & 2 & 0 & 4 \\
HMI & 24 & 8 & & & 0 & 4 \\
Simulation & 16 & & 2 & & 0 &
\end{tabular}

\section{Functional Validation}

The HMI required three days starting with a rapid prototype on a non-real-time simulation for specification of the requirements. The further development was done under supervision of the customer. During this period the operator got familiar with the system and trained the operation on the simulator. This procedure ensured that the HMI fulfills the customer's needs and the system could be handled immediately after the real start-up of the machine.

\section{Factory Acceptance Test (FAT)}

With the implementation of the HMI on the real-time simulator, which had the original PLC as hardwarein-the-loop, a factory acceptance test was carried out. After this, the real start-up was initiated.

\subsection{Start-up of the System}

Tab. 1 shows the improvements due to simulation in the project. Virtual start-up and FAT on the virtual system took place before the installation phase and consequently reduced the amount of work at the customer's site (corresponding fields are highlighted in the table). From experience with former projects without simulation we conclude that the amount of hours would be at least two times higher, when the work had to be done after the installation. Due to the thorough simulation, the training could be completed before the deployment. From the table it can be seen, that the work required after delivery mainly consisted of assembling and cabling of the control system. The DC drives (row 2 in Tab. 1) were operable immediately after turning on, the control parameters required only slight optimization.

Some hours in the production phase were necessary to correct for an effect that was not regarded in the simulation work: The mutual influence of the two bodies' angular momentum was not included in the model (Fig. 7) and appeared to be essential, when the evacuation of the chamber reduced the friction of the axes' seals. This problem, which occurred at certain recipes, had to be fixed in the production phase.

It is remarkable that the production was started in the absence of developers and constructors without any problems or interruptions caused by the automation system. No batch of items to be coated was lost. Some minor changes of units for more comfort were requested and implemented during a convenient time without losing production time.

Tab. 1 does not show the amount of work for the requirement analysis and planning of the system, since this is not influenced by the simulation work.

\section{CONCLUSIONS}

Simulation is widely used in many branches of industry with a variety of different applications. In the actual project simulation for a small production system was applied and the effects were investigated.

For a PVD (physical vapor deposition) coating process for materials, which involves pulsed laser deposition and magnetron sputtering, a laser target manipulator and a carrier carousel for the substrates to be coated were automated with a PLC (programmable logic controller).

The expense of additional hardware dedicated to simulation was brought to zero by embedding the simulation model directly on the PLC, running parallel and communicating directly with the control program. 


\section{Rath, Lackner, and Waldhauser}

This real-time hardware-in-the-loop (HIL) simulation was used for a virtual start-up, which allowed to eliminate errors and to adjust parameters before the start-up of the real machine.

Modern PLCs allow an emulation of their behavior on the PC, leading to a system that comprises the behavior of the complete mechanical, electrical, electronic and software equipment. It runs on a single PC and does not require any additional hardware. With this configuration, an efficient simulation for functional validation was available. It was used to study the process (process trainer), to specify, develop and validate the human-machine-interface (HMI), and finally to train the operation of the system.

With the real-time simulation on the dedicated PLC hardware including the HMI, a factory acceptance test (FAT) was performed.

The most important benefit found during the project was a fast start-up of the machine. The production start was initiated by the customer without support of the developers. No waste material was produced and no fault report was necessary.

It turns out that even for small automation projects simulation is affordable and yields faster start-up of the plant while reducing risks and errors.

\section{ACKNOWLEDGMENTS}

Financial support of this work by the Austrian Federal Ministry of Traffic, Innovation and Technology, the Government of Styria and the European Union is highly acknowledged.

\section{REFERENCES}

Beck, K. 1999. Extreme Programming Explained: Embrace Change. first ed. Boston, USA: Addison-Wesley Professional.

Chrisey, D., and C. Hubler. (Eds.) 1994. Pulsed Laser Deposition of Thin Films. New York: Wiley.

Crosbie, R. 2012. "Real-Time Simulation using Hybrid Models". In Real-time Simulation Technologies: Principles, Methodologies, and Applications, edited by K. Popovici and P. Mosterman, 3-33. Boca Raton, FL: CRC Press.

Ebner, R., W. Waldhauser, and W. Lenz. 2001. "Pulsed laser deposition: A new technique for coating sheet materials and three-dimensional industrial components". In Materials Week. Munich. Paper No. 575.

Filla, R., and J. Palmberg. 2003. "Using Dynamic Simulation in the Development of Construction Machinery". In The Eighth Scandinavian International Conference on Fluid Power, SICFP03, edited by T. Koskinen and M. Vilenius, 651-667. Tampere.

Freedman, P. 2000. "New Drill Jumbo Operator Training Simulator". IEEE Canadian Review 34:16-18.

Isermann, R., J. Schaffnit, and S. Sinsel. 1999. "Hardware-in-the-loop simulation for the design and testing of engine-control systems". Control Engineering Practice 7(5):643-653.

Lackner, L., and W. Waldhauser. 2005. "HybridPLD - Pulslaser-Hybridbeschichtung im industriellen Maßstab". In Jahrbuch Oberflächentechnik 2005, edited by R. Suchentrunk, Volume 61, 128-137. Bad Saulgau, Germany: Leuze.

Lieberman, B. 2007. The Art of Software Modeling, 17. Boca Raton, FL: Auerbach Publications.

Page, R. 2000. "Brief History of Fligth Simulation". In SimTecT 2000 Proceedings, Sidney, 11-17.

Pedgen, C., R. Shannon, and R. Sadowski. 1995. Introduction to Simulation Using SIMAN. second ed. Singapore: McGraw-Hill.

Perkins, T. 1985. "Simulation technology in operator training. Full-scope plant-specific simulators are part of the new reality". IAEA Bulletin 27 (3): 18-24.

Pfeiler, H., N. Köck, J. Schröder, and L. Maestrutti. 2003. "The new rail mill of voestalpine Schienen at Donawitz". MPT International 26 (6): 40-44.

Rath, G. 2008. "Training Simulator for Rolling Mill Maintenance". In Advances in Simulation for Production and Logistics Applications, edited by M. Rabe, 189-198. Fraunhofer IRB, Stuttgart. 


\section{Rath, Lackner, and Waldhauser}

Waldhauser, W., and J. Lackner. 2006. "Room-temperature Industrially-scaled Pulsed Laser Deposition of Coatings for Wear-protection, Low-friction and Decorative Applications". In Proc. 49th Annual Technical Conference - Society of Vacuum Coaters, 36-40. Washington D.C.

Walters, B. 2000. "Embedded Simulation, Training at its Best". Website. Accessed April 3, 2012. http: //www.thefreelibrary.com/Embedded+Simulation,+Training+at+its+Bes\%t-a070367446.

Zeigler, B. 1976. Theory of Modeling and Simulation. first ed. New York: Wiley Interscience.

\section{AUTHOR BIOGRAPHIES}

GERHARD RATH received the degree of an "Dipl- Ing.", which is equivalent to M.Sc., in electro technical engineering at the Technical University of Graz. He was developing liquid handling and detection systems at Salzburger Labortechnik GmbH (now Tecan), then responsible for software development for cold rolling mills at Andritz AG, Austria. At Joanneum Research, Austria, he was manager in several development projects for supervisory control systems. Writing his doctoral thesis about cold rolling mill control, he was employed at the University of Leoben, where he received his Ph.D. degree. Teaching activities are in the fields of automation, control theory, signal processing, modeling and simulation. His research projects deal with hydraulic systems of mining machines, real-time systems and hardware-in-the-loop simulation. His email address is gerhard.rath@unileoben.ac.at.

JÜRGEN M. LACKNER studied materials science at the University of Leoben after the secondary school qualifications at the technical college for mechanical engineering and metallurgy in Leoben. He finished his study with a diploma thesis about the topic "Tensile tests for high-strength materials" (powder metallurgical high speed steels with tensile strengths up to $3000 \mathrm{MPa}$ ) in April 2001. Subsequently he was employed at the Institute for Physical Metallurgy and Materials Testing (University of Leoben) as well as at the Materials Center Leoben. In this time he worked on projects on the development of the Pulsed Laser Deposition technique and optical and tribological coatings deposited with this technique. Several publications as well as his Ph.D. thesis with the title "Innovative coating by Pulsed Laser Deposition" were created from results of these projects, which were performed in cooperation with the Laser Centre Leoben. Besides the participation in these projects teaching of physical metallurgy and materials testing in various lectures at the University of Leoben complemented his area of responsibility. Since July 2003 he works as a research engineer and project manager at JOANNEUM RESEARCH. His email address is juergen.lackner@ joanneum.at.

WOLFGANG WALDHAUSER was awarded a M.Sc. (Materials Science) by the University of Mining, Metallurgy and Materials in Leoben for his master thesis on "Evaluation of anodic coatings on small decorative aluminum parts". From 1992 to 1999 he worked as scientific assistant at the Department of Physical Metallurgy and Materials Testing of the University of Leoben and finished his studies with a doctoral thesis on "Deposition and characterization of sputtered hexaboride coatings". Since 1999, Wolfgang Waldhauser works as a research engineer and project manager at the Leoben Laser Center. His areas of experience and interest cover development of processes and coatings in the field of laser assisted thin film technology and characterization and applications of thin films. He has published numerous papers within his research areas. Since 2010 he is head of the research group Functional Surfaces at the Institute of Surface Technologies and Photonics of JOANNEUM RESEARCH. He is member of Deutsche Gesellschaft für Materialkunde (DGM) and Arbeitsgemeinschaft Oberflächentechnik (ARGE OT). His email address is wolfgang.waldhauser@joanneum.at. 